\section{Political Identities and Science Learning}

\section{Julia Svoboda Gouvea*}

Tufts University, Education, 310 Paige Hall, Medford, MA 02144

\begin{abstract}
Science instruction has largely avoided engaging students in political issues. Recent scholarship is drawing attention to the ways in which students' political identities influence science learning and the need for science learning that engages with students' political beliefs and values. In this Current Insights, I explore emerging work that provides a launching point for research and teaching at the intersection of political and science learning.
\end{abstract}

\section{INTRODUCTION}

Science curricula and instruction have historically avoided explicit attention to political issues, preferring to appear neutral and objective. In recent, years scholars have challenged apolitical, value-free approaches to teaching science, arguing that regardless of whether or not political issues are explicitly engaged, students are developing political identities, values, and beliefs about the role of science in society (e.g. MoralesDoyle et al., 2020).

In this issue, I highlight an emerging line of research that examines how students' political identities influence and are influenced by science learning. As a set, these articles draw attention to the role of political identities in learning, propose mechanisms that begin to explain how political identities and learning are intertwined, and describe approaches to instruction that explicitly integrate political and ethical concerns into STEM learning environments.

\section{POLITICAL IDEOLOGY AND LEARNING ABOUT CLIMATE CHANGE}

Zummo, L., Donovan, B., \& Walsh, K. (2021). Complex influences of mechanistic knowledge, worldview, and quantitative reasoning on climate change discourse: Evidence for ideologically motivated reasoning among youth. Journal of Research on Science Teaching, 58, 95-127. DOI: 10.1002/tea.21648

Among adults, political orientation is a predictor of acceptance of or skepticism towards anthropogenic climate change. In this study, Zummo and colleagues sought to understand if similar associations held among adolescents (aged 11-14). More specifically, they designed a study to examine support for three social-psychological hypotheses:

- The worldview hypothesis proposes that both political affiliation and beliefs about climate change stem from an underlying worldview that characterizes whether one is more concerned about risks to personal freedoms (hierarchical/individualist) or more concerned with environmental risks to communities (egalitarian/ communal).

- The worldview, quantitative reasoning interaction $(W \times Q R)$ hypothesis proposes that knowledge and experience with quantitative reasoning can amplify worldview beliefs in opposite directions: more experience with quantitative reasoning could strengthen acceptance of climate change among those with egalitarian/communal worldviews, while strengthening skepticism among those with hierarchical/ individualist worldviews.

- A third hypothesis proposes that it is actually one's mechanistic understanding of climate change that matters. Gaining knowledge about climate change could potentially "override" worldview or $\mathrm{W} \times \mathrm{QR}$ based rejection.
CBE Life Sci Educ September 1, 2021 20:fe5 DOI:10.1187/cbe.21-07-0173

*Address correspondence to: Julia Svoboda Gouvea (julia.gouvea@tufts.edu).

(c) 2021 J. S. Gouvea. CBE-Life Sciences Education ( 2021 The American Society for Cell Biology. This article is distributed by The American Society for Cell Biology under license from the author(s). It is available to the public under an Attribution-Noncommercial-Share Alike 3.0 Unported Creative Commons License (http://creativecommons.org/licenses/ by-nc-sa/3.0)

"ASCB $®$ " and "The American Society for Cell Biology ${ }^{\circledR}$ " are registered trademarks of The American Society for Cell Biology. 
The researchers sampled 357 high school students from 46 classrooms across the U.S. They used a randomized controlled experimental design to assign half of the students in each classroom to experimental or control conditions. Both groups completed a 30-minute self-directed computer module, but the experimental group received information causally linking humans to climate change (i.e. via greenhouse gases), while the control group received additional descriptive information about climate trends.

For all students, researchers assessed worldview (through a cultural risk survey) and quantitative reasoning (QR) (through a problem-solving instrument). They also analyzed students' written responses to a fictional peer who "thought climate change was not real," coding them as either accepting or rejecting climate change depending on whether the writing included expressions of concern or dismissal. The researchers then used linear modeling techniques to examine the extent to which worldview, QR, and the knowledge intervention were associated with acceptance or rejection of climate change.

The authors argue that their results provide some support for all three hypotheses. The knowledge intervention significantly increased the odds $(\mathrm{OR}=2.9)^{1}$ of students' acceptance of climate change. In addition, higher worldview scores (more hierarchical/individualistic) reduced odds of acceptance (OR = 0.157). There was no significant interaction between worldview and knowledge, meaning that the increase in acceptance was independent of students' expressed worldviews.

Despite the significant impact of the intervention, most of the variation among students is explained by worldview, which accounts for roughly 12 times the variance than the intervention. Therefore, the authors conclude that political worldview impacts adolescents' views about climate change as it does in adults. They also argue that an effect from such a brief intervention is suggestive of the promise of education in impacting these views.

In addition, the researchers report a significant interaction between worldview and QR, with higher QR scores slightly increasing odds of acceptance (OR $=1.046)$ for communal/ egalitarian worldviews and more strongly decreasing odds of acceptance for individualist worldviews $(\mathrm{OR}=0.862) .^{2}$ Qualitative analyses of students' written work led the authors to speculate that while high familiarity with QR led to more engagement with data and more acceptance of climate change for students with communal/egalitarian worldview scores, high QR in students with hierarchical/individualist views led them to dismiss data or attend to variation as evidence that climate change is a natural process. These results suggest a need to attend to QR in climate change learning.

Overall while this study indicates that political identities impact acceptance of climate change, it raises questions about how to more thoroughly engage with these aspects of students' identities in classrooms. The next paper provides an example of a more in-depth integration of political issues into a science curriculum and an examination of the impact on students' learning and emotions.

\footnotetext{
${ }^{1}$ An odds ratio (OR) is a measure of association, where 1 indicates no association, $>1$ indicates a positive association and $<1$ indicates a negative association.

${ }^{2}$ That is, the odds are increased by 0.046 and decreased by 0.174 .
}

\section{LEARNING AND EMOTION WHEN TEACHING SCIENCE AS POLITICAL}

Davis, N. R., \& Schaeffer, J. (2019). Troubling Troubled Waters in Elementary Science Education: Politics, Ethics \& Black Children's Conceptions of Water [Justice] in the Era of Flint. Cognition and Instruction, 37(3), 367-389. https:// doi.org/10.1080/07370008.2019.1624548

Water is a common topic in the elementary school science curriculum. Students typically learn about its structure, properties, and the "water cycle." Davis and Schaeffer describe a curriculum (designed by Schaeffer, a teacher, in collaboration with administrators) to engage Black elementary school students in sociopolitical analyses of water. The "water is life" unit embeds scientific understandings of water in discussions about water rights and water justice. A key feature of the design was connection to place -- students learned about the water crisis in Flint and discussed water shut-offs in their own city.

Davis and Schaeffer critically engage with prior work suggesting that discussing environmental or political crises may be emotionally overwhelming for young children. They suggest that such feelings may not be generalizable, and, in particular, that engaging young Black children in a meaningful local issue may evoke more complex emotional responses. Thus, they examined both what children learned from this unit as well as the role of affect in their learning.

Using a critical ethnographic approach, Davis collected field notes and photographs over a period of two years of observation. She also conducted two interviews with 19 children. Davis and Schaeffer then used thematic and interpretive coding to examine shifts in students' scientific, moral, and political stances towards water. They describe key shifts evident in their findings.

One key shift describes how students' early understandings of water as a commodity gave way to understandings of water as a need and right. For example, early on students framed water as something that must be paid for, but later questioned the morality of shutting off something that people "need to live." Relatedly, students shifted the locus of the problem from individuals (who didn't pay) to systems (that control water access). Finally, while students initially reacted with fear and sought to distance themselves from Flint, by the end of the unit, students expressed a sense of concern and anger that the government would not do more to help those in need.

Davis and Schaeffer argue that the curriculum allowed students to connect scientific understandings of water as necessary for life with socio-political issues about water justice. They propose that this was made possible by the placed-based aspect of the curriculum that linked the crisis in Flint to local issues of water shut-offs familiar to these students.

They also argue that while fear and shock were somewhat attenuated by engagement and agency, students did not stop feeling upset about these problems. The authors argue that experiencing fear and anger are appropriate responses to recognizing injustices and are not a sufficient reason to shield children from difficult topics. They do add, however, that not all political engagement should center on crisis and that socio-scientific science teaching must also invite "children to consider how scientific expertise might be leveraged towards the just futures they desire" (p. 386). 
The next article presents a way to envision how attending to politics in STEM can be empowering and proposes a theoretical construct that can help researchers and educators think about the processes of political and disciplinary identity development as intertwined.

\section{CO-DEVELOPMENT OF POLITICAL AND DISCIPLINARY IDENTITIES IN STEM}

Vakil, S. (2020). "I've Always Been Scared That Someday I'm Going to Sell Out": Exploring the relationship between Political Identity and Learning in Computer Science Education. Cognition and Instruction, 38(2), 87-115. https:// doi.org/10.1080/07370008.2020.1730374

Vakil's stated purpose is to explore "how political identity functions in learning environments." He does this first by conceptualizing learning in STEM as including a process of disciplinary values interpretation. This process entails both how students learn about the values of a discipline as well as how they learn about who they are and who they can become in that discipline. Vakil proposes that tensions or alignments between how students make sense of disciplinary values and their own identities are consequential for learning and persistence in STEM, perhaps especially for students from marginalized communities.

Vakil provides an empirical grounding for this idea by illustrating how disciplinary values interpretation plays out in a high school computer science class. The focus of his research is a 10-wk project-based unit on "technology for social good." Vakil studied 12 students from 7 different project teams, collecting data in the form of video, field notes, questionnaire responses and interviews. He used these data to describe students' incoming political and disciplinary identities, how these were enacted and influenced learning during the project, and evidence of how participation shifted aspects of students' identities.

From this analysis Vakil chose to report on two students, Stacey and Lupe, because they both had strong disciplinary identities as computer science students, but had different incoming political and racial identities.

Stacey, a sophomore planning to major in CS, identified as mixed-race. Early on she expressed ideas about equity as a problem of individual effort, pushing back against structural explanations. Her group decided to create an app that would help students navigate a shadowing program that paired new and experienced students at their school. Stacey's political ideas showed up initially as support for a race-neutral version of the app. Over the course of the project, Stacey began to notice issues of underrepresentation as linked to structures and came to see herself as someone who could "use technology to make her community better."

Lupe was a high achieving student of mixed Mexican descent. Politically, she framed issues around race and gender at her school as structural and expressed concern for the tensions between her political identity as a feminist and her desire to pursue computer science as a career. Her group project led to the creation of "STEM gal", a video game designed to help girls of color resist negative stereotyping by modeling how to confront racist/sexist remarks and build solidarity. Her identity clearly impacted this work, and the project also opened up a possibility for Lupe to be political within computer science.

Vakil articulates several implications of this work. First, political identities matter and they can be shifted through learning experiences. Second the explicit attention to political theme of a "social good" was important in this case and suggests that design that intentionally includes political issues can serve as context where political and disciplinary learning can interact. Finally, Vakil draws attention to political identity as a new way to understand why students, particularly those from underrepresented groups, de-identify with disciplines that don't provide ways to see themselves in the values of the discipline.

\section{QUESTIONS FOR BIOLOGY EDUCATION}

It is notable that these three articles all report on research in K-12 settings, suggesting a need for more work at the collegiate level. For biology educators and researchers specifically, these articles raise a number of possible questions. What political identities and values do students bring into undergraduate and graduate biology learning environments, and to what extent do they experience alignment or tension with the disciplinary values they encounter? To what extent does college biology instruction influence both disciplinary and political identities? What might it look like to design university-level biology learning environments with attention to social, political and racialized issues? How might such designs evoke different emotions, inspire actions, or influence how students see themselves as biology students and citizens?

\section{REFERENCE}

Morales-Doyle, D., Vossoughi, S., Vakil, S., \& Bang, M. (2020, August). In an Era of Pandemic and Protest, STEM Education Can't Pretend to Be Apolitical. Truthout, Retrieved June 18, 2021, from https://truthout.org/ articles/in-an-era-of-pandemic-and-protest-stem-education -cant-pretend-to-be-apolitical/ 